\title{
Possibilidades formativas para os docentes universitários: compromisso institucional
}

\section{Training possibilities for university teachers: institutional commitment}

\author{
Elena Maria Billig Mello* \\ Diana Paula Salomão de Freitas**
}

\begin{abstract}
RESUMO
Este texto é fruto de uma reflexão teórica sobre a formação dos docentes do ensino superior, com base em uma pesquisa-ação desenvolvida com servidores de uma universidade federal situada no Rio Grande do Sul (RS). Os elementos trazidos à discussão são resultados da pesquisa-ação (BARBIER; THIOLLENT) desenvolvida sobre a formação continuada por meio de Cursos de Formação Pedagógica fomentados pela gestão e desenvolvido em campi da Universidade, considerando a concepção de desenvolvimento profissional docente (ALMEIDA; PIMENTA; RIOS). A formação ofertada configura-se como uma das ações da pedagogia universitária (CUNHA; FRANCO) em construção na Instituição. Os resultados do trabalho foram analisados por meio de análise textual discursiva (MORAES; GALIAZZI). A matriz teórico-conceitual tem como base a metodologia dialética de construção do conhecimento (VASCONCELLOS). Os resultados encontrados por meio da análise textual discursiva corroboram a fundamentação teórica adotada neste trabalho e na própria Universidade quanto ao fenômeno da formação docente como um elemento crucial à qualidade da educação.

Palavras-chave: Formação docente. Pedagogia universitária. Metodologia dialética.
\end{abstract}

* Universidade Federal do Pampa. Uruguaiana, Rio Grande do Sul, Brasil. E-mail: profelena@gmail.com. http://orcid.org/0000-0003-0366-3021

** Universidade Federal do Pampa. Bagé, Rio Grande do Sul, Brasil. E-mail: disalomao@ gmail.com. http://orcid.org/0000-0001-6944-2219 


\begin{abstract}
This text is the result of a theoretical reflection about the higher education teachers' Training Process fomented by the management process in a federal university located in Rio Grande do Sul/Brazil. Considering the conception of professional teacher development (ALMEIDA; RIOS) we brought for discussion the results of the action research (BARBIER; THIOLLENT) developed by a Course offered, as one of the actions of the university pedagogy (CUNHA; FRANCO), under construction in the Institution. The results of the study were analyzed by Textual Discursive Analysis (MORAES; GALIAZZI). The theoretical-conceptual matrix is based on the dialectical methodology of knowledge construction (VASCONCELLOS). The results found through the Textual Discursive Analysis corroborate the theoretical foundation adopted in this work and the University itself regarding the phenomenon of teacher education as a crucial element to the quality of education.
\end{abstract}

Keywords: Teacher training. University pedagogy. Dialectical methodology.

\title{
Mobilização para o conhecimento: o contexto da pesquisa
}

Refletir para apresentar proposições à formação de professores universitários no Brasil é premente pela expansão da oferta de Educação Superior, em período anterior, a partir do Programa de Apoio à Reestruturação e Expansão das Universidades Federais (BRASIL, 2007), em que vivemos um aumento significativo e diversificado de novos sujeitos sociais que passaram a frequentar as universidades (FRANCO, 2012, p. 22). Nesse contexto, o papel formativo das instituições superiores se tornou mais complexo em virtude da "massificação e diversificação do perfil estudantil, presença de estudantes trabalhadores, ampliação dos cursos noturnos, incorporação das novas tecnologias, facilidades de acesso ao conhecimento, além da emergência de novas demandas formativas apresentadas pela sociedade" (ALMEIDA, 2012, p. 30-31).

Tais exigências convocaram que, para além da observação, análise e avaliação das possibilidades (THIOLLENT, 1998) realizadas pela pedagogia universitária, fossem proporcionados subsídios para o exercício deste "campo específico de intervenção profissional na prática social” (PIMENTA, 2012, p. 11). Situamos que, como as demais instituições de Educação Superior, a Universidade assumiu como missão promover a Educação Superior de qualidade, pela integração entre ensino, pesquisa e extensão, com vistas a formar sujeitos comprometidos e capacitados para atuarem em prol do desenvolvimento regio- 
nal, nacional e internacional. A instituição educacional, que nos proporcionou as condições paras realizar as ações reflexionadas neste texto, foi legalmente criada e estruturada como uma universidade multicampi, cujas unidades acadêmicas (os Campi) estão localizadas nas regiões da Fronteira Oeste, do Sul e da Campanha do Rio Grande do Sul, Brasil.

Nas políticas institucionais de ensino do Projeto Institucional (PI) encontra-se como um dos objetivos a ampliação do acesso e da permanência dos estudantes, com garantia de continuidade nos estudos. Nesse sentido, acrescentamos que, na compreensão de que os docentes universitários também são sujeitos inconclusos (FREIRE, 2001), a implantação de políticas de formação continuada tem como foco contribuir com a formação permanente dos professores e, por consequência, a melhoria do processo ensino-aprendizagem. Fruto do trabalho coletivo da comunidade acadêmica, esse Projeto Institucional foi atualizado em 2013, resultando no Plano de Desenvolvimento Institucional (PDI), com validade para o período 2014-2018. Dessa forma para realizar o perfil, a visão e a missão institucional, o PDI está organizado em quatro eixos estruturantes, a saber: Excelência Acadêmica; Aperfeiçoamento Institucional; Dimensão Humana; e Compromisso Social. Neste atual PDI, há referência às políticas de aperfeiçoamento do corpo docente e seus três pilares (docência como profissão, práticas de formação e reflexão sobre a prática), que devem possibilitar o crescimento profissional e ampliar o conhecimento do corpo docente sobre as bases que poderão gerar consciência crítica e suporte para a organização política, social e econômica do ambiente à sua volta.

$\mathrm{O}$ assessoramento pedagógico docente tem como objetivo investigar, analisar e intervir nos processos de ensino e aprendizagem institucionais. Entre as ações está a organização do Programa de Desenvolvimento Profissional Docente, que contém os projetos e ações voltados à formação continuada dos docentes da Universidade, visando à melhoria contínua da qualidade de ensino. Sua estrutura centra-se nas discussões de perspectivas atuais para Educação Superior; no contexto social e no desenvolvimento profissional docente, sob a perspectiva formativa da pedagogia universitária. Constitui-se em uma política institucional de formação continuada, sustentada em três pilares: (a) docência como profissão que se constrói permanentemente e, por isso, tem a necessidade de uma atenção sobre novas práticas e inovações nas áreas do conhecimento; (b) práticas de formação que tomem a dimensão coletiva, possibilitando a percepção de unidade da Universidade e também da diversidade nas mais diversas formas de atuação do docente; (c) reflexão sobre a prática, com o uso de experiências dos próprios docentes como forma de gerar debate, reflexão, aprendizado e aperfeiçoamento das suas atividades. 
O Programa supramencionado foi dividido em três projetos que se complementaram, a saber: (a) Projeto de Acolhida e Acompanhamento do Professor Ingressante; (b) Projeto de Aperfeiçoamento à Docência Superior; e (c) Projeto de Qualificação da Gestão do Ensino. Especificamente, objetiva-se com o Programa: (a) promover ações de formação continuada dos docentes, numa forma de garantir o aperfeiçoamento pedagógico; (b) fomentar, nas atividades docentes, a indissociabilidade entre ensino, pesquisa e extensão; (c) favorecer a partilha de experiências pedagógicas entre os docentes; (d) incentivar o desenvolvimento de pesquisas e metodologias para o ensino superior; (e) assessorar os docentes no planejamento de suas atividades curriculares e de ensino propondo alternativas metodológicas a partir de reflexões coletivas; (f) dar continuidade na promoção de encontros e reuniões com temas relevantes, identificados com base na observação e na análise da realidade, visando efetivar a proposta institucional; (g) estimular o uso de recursos tecnológicos disponíveis na Instituição; (h) analisar e refletir sobre o sistema de avaliação adotado na Universidade; (i) produzir informações significativas que subsidiem o trabalho com o discente e (j) constituir-se espaço de produção e socialização de conhecimento sobre os processos de ensino e aprendizagem na perspectiva da pedagogia universitária.

Entre as várias ações promovidas nesse Programa, como parte do Projeto de Aperfeiçoamento à Docência, foi desenvolvido entre 2013 e 2015, o Curso de Formação Pedagógica, ofertado localmente aos docentes e técnicos das Unidades Universitárias. Essa ação, objeto da pesquisa socializada no presente trabalho, será analisada no próximo item do texto.

\section{Construção do conhecimento: pesquisa-ação no desenvolvimento da formação do docente universitário}

Este trabalho é resultado de reflexões teóricas da pesquisa-ação que desenvolvemos a partir do Curso de Formação Pedagógica, integrante do Projeto de Aperfeiçoamento à Docência. Esta pesquisa social com base empírica tem o duplo objetivo de transformar a realidade e produzir conhecimentos relativos a essas transformações (THIOLLENT, 1998; BARBIER, 2007).

O referido Curso foi organizado pela necessidade de contribuir com a formação didático-pedagógica dos professores universitários, pela necessidade de aprofundar os conhecimentos históricos, sociais, culturais e organizacionais da atividade docente (PIMENTA, 2012, p. 12), valendo-se da retomada de procedimentos relacionados aos componentes didático-pedagógicos dessa prática 
educativa. Outro indicador importante nesse processo de formação foi relativo ao fato de a maioria dos docentes da Instituição ter pouca ou nenhuma experiência na docência universitária, por serem aprovados no concurso público em seguida do término do mestrado ou do doutorado. Nesse sentido, a formação pedagógica, proposta em forma de curso, visou à valorização e partilha de diferentes experiências e saberes ao provocar, no coletivo dos docentes, reflexões acerca de como construir e qualificar a mediação para aprendizagem dos estudantes.

Concordamos com Thiollent (1998, p. 102) quando afirma que: "A resolução de problemas efetivos se encontra na coletividade e só pode ser levada adiante com a participação dos seus membros", ainda que como meio de sensibilização e de tomada de consciência. Assim, também consideramos que "a metodologia da pesquisa-ação constitui um modo de pesquisa, uma forma de raciocínio e um tipo de intervenção" (THIOLLENT, 1998, p. 192) adequada ao enfrentamento da ideia problemática de que os docentes universitários são bons ensinadores, já que possuem conhecimento do campo científico da área, construído na formação em nível superior na graduação e pós-graduação, acrescido, algumas vezes, dos saberes exercitados no mundo do trabalho.

Ao contrário disso, juntamente com Almeida e Pimenta (2011), Cunha (2006), Diniz-Pereira (2008), entendemos que essa compreensão, ao mesmo tempo em que desprestigia e desvaloriza a profissão, por considerar que quem conhece o conteúdo das diversas áreas do saber sabe "automaticamente" ensinar, também afasta da necessidade da formação permanente, dos espaços e tempos para o desenvolvimento pedagógico-profissional que, na reflexão da prática, colabora para melhorá-la, tornando profissionais que fazem bem a prática educativa que lhes faz bem, compromissados com as demandas do mundo atual (RIOS, 2008).

Nesse entendimento, o Curso de Formação Pedagógica ${ }^{1}$ foi percebido como espaço de participação para explicitação, discussão e proposições à formação identitária e profissional dos professores. Participação à maneira concebida por Guedes Pinto, pela qual "Participar não é assistir nem fazer parte, é tomar parte nas coisas do planejamento, na tomada de decisões e na execução dos programas e projetos.”. (GUEDES PINTO, 1987 apud DUQUE-ARRAZOLA; THIOLLENT, 2014, p. 15) (grifos nossos).

Para essa etapa da pesquisa-ação, em que levantamos elementos para subsidiar as discussões acerca do desenvolvimento profissional valendo-nos de

1 A $1^{\text {a }}$ edição do curso foi realizada de dezembro de 2013 a agosto de 2014, com duração de $24 \mathrm{~h}$, organizado em três dias de formação, em cada Campus. A $2^{\mathrm{a}}$ edição iniciou em agosto de 2015 e foi ofertado até o final de dezembro de 2015, com carga horária de 16h, organizado em dois dias, em cada Campus. 
registros produzidos por integrantes da pró-reitoria de graduação, realizamos análise que se aproxima do que Moraes e Galiazzi (2007) denominam análise textual discursiva. Consideramos que, neste trabalho, realizamos o início da pesquisa-ação, pois segundo Barbier (2007, p. 55): "Na pesquisa-ação a interpretação e a análise são o produto das discussões de grupo". Assim, com base na teorização das categorias mais recorrentes na análise de relatos produzidos neste processo, buscamos argumentar que os cursos de formação pedagógica, com foco nos docentes iniciantes na carreira universitária, ao ser assumido como uma responsabilidade institucional favorece espaços de valorização do desenvolvimento profissional, na medida em que amplia a consciência sobre o ser professor; o saber ser professor $\mathrm{e}$, fundamentalmente, o poder ser professor (ALMEIDA, 2012) e seu significado enquanto prática social.

Optamos por realizar procedimentos pertinentes à análise textual discursiva dos registros para perceber contribuições à prática dos docentes universitários participantes dos encontros de formação pedagógica. Isso porque:

Realizar pesquisas utilizando a análise textual discursiva implica em assumir uma atitude fenomenológica, ou seja, deixar que os fenômenos se manifestem, sem impor-lhes direcionamentos. É ficar atento às perspectivas dos participantes. Essa abordagem valoriza argumentos qualitativos movendo-se do verdadeiro para o verossímil, daquilo que é provado por argumentos fundamentados na lógica formal para o que é fundamentado por meio de uma argumentação dialética rigorosa. (MORAES; GALIAZZI, 2007, p. 31).

Diante disso, ademais de descrever o processo de formação realizado, assumimos a pesquisa-ação (BARBIER, 2007; THIOLLENT 1980; DUQUEARRAZOLA; THIOLLENT, 2014) como modo de possibilitar a transformação da prática político-pedagógica dos docentes.

O movimento da análise iniciou com leitura dos registros dos profissionais da equipe da pró-reitoria de graduação que acompanharam a formação, o que consideramos o corpus de análise. Neste buscamos separar e codificar excertos dos registros com sentido em si, o que, na análise textual discursiva (MORAES; GALIAZZI, 2007), aproxima-se do que os autores denominam unidades de significado. Para agrupar as unidades de significado com sentido semelhante, encontramos nos registros elementos constitutivos da ação docente, o que, para Almeida (2012), são desconhecidos cientificamente pelo professor universitário que "não tem uma formação voltada para os processos de ensino-aprendizagem" 
(ALMEIDA, 2012, p. 67). Apresentaremos, a seguir, os acontecimentos do Curso e os conhecimentos oriundos da abordagem qualitativa dos registros analisados.

\section{Elaboração e expressão da síntese: contribuições do curso de formação pedagógica para a prática dos docentes universitários}

Conforme planejado, o Curso de Formação Pedagógica foi realizado nos dez Campi da Universidade. Desses, participaram da $1^{\mathrm{a}}$ edição do Curso 252 servidores, incluindo as autoras deste texto. Da $2^{\mathrm{a}}$ edição do Curso, no presente texto, analisamos os registros feitos em quatro dos dez Campi, contando com a participação de 142 servidores.

Neste item descreveremos as práticas educativas realizadas no referido Curso, articulando os acontecimentos e manifestações registrados com referências teóricas que dão sustentação ao campo da pedagogia universitária. A base teórico-metodológica de explicitação desta síntese do conhecimento, resultado da pesquisa-ação, principalmente da análise textual discursiva realizada quanto ao Curso e seus desdobramentos à formação pedagógica, também está estruturada na concepção dialética, que perpassou todo o desenvolvimento metodológico do Curso.

\section{Mobilização para o conhecimento}

Iniciamos relatando que previamente ao desenvolvimento do Curso foram disponibilizados, pela professora-mediadora, materiais para fundamentação teórico-epistemológica que fomentaram a discussão e reflexão docente a respeito de práticas pedagógicas no ensino superior. Esse momento mobilizador foi providenciado e organizado pela unidade gestora do Curso, por meio do contato prévio com as Unidades Acadêmicas, quanto à organização necessária ao Curso e, principalmente, com o coletivo de docentes inscritos em cada uma dessas Unidades, considerando suas áreas de conhecimento. Entre as providências, uma das estratégias centrais foi a disseminação de materiais para os cursistas, bem como da ementa e objetivos do Curso.

Na contextualização dessa oferta, foi mencionada a avaliação institucional realizada nos anos de 2011 e 2012 após a realização de seminários docentes. Nessas avaliações, os docentes manifestaram a necessidade de atividade forma- 
tiva de outra natureza, que abarcasse a questão da prática docente de acordo com as peculiaridades e realidades dos cursos/Campi, para além da formação geral que era oferecida. Assim, entendemos que essa era uma demanda e passamos a buscar formas para viabilizar a proposta advinda das avaliações. A primeira alternativa encontrada, tratada como piloto, foi a de ofertar o Curso em cada um dos dez Campi, conforme descrito neste texto. Acreditamos que essa situação providenciada, além de ser mera etapa de organização, revela-se por si só o distanciamento da noção de "palestra" ou "evento", prática muito comum em formações, abrindo outro sentido para a formação realizada com base nos fundamentos teórico-metodológicos aqui já enunciados.

Quanto ao momento presencial do Curso, como mobilização para a construção do conhecimento, a professora-mediadora apresentou duas provocações iniciais que versaram sobre: (a) como os docentes poderiam qualificar a mediação da aprendizagem dos estudantes, a partir das aprendizagens decorrentes do Curso e (b) qual a expectativa dos docentes quanto aos momentos de aprendizagem favorecidos pelo Curso no que diz respeito ao impacto positivo de suas ações pedagógicas na vida dos acadêmicos. Com essa atividade, foi possível construir o perfil da turma de cursistas e realizar a adequação dos conteúdos e métodos que seriam utilizados, atentando para a situação real de conhecimentos dos participantes e suas expectativas de aprendizagem.

A partir disso foi revelado que, em média, $68,8 \%$ dos docentes participantes tinham apenas entre três e cinco anos de experiência como profissional na Educação Superior e, aproximadamente, apenas $10 \%$ possuíam mais de 20 anos de experiência nesse nível de ensino. A maioria desses professores estava interessada no Curso; entretanto, de início, alguns se mostraram resistentes em trabalhar assuntos relacionados à pedagogia universitária, o que foi sendo modificado com o envolvimento de todos os professores à medida que perceberam a importância desse espaço de formação e, principalmente, pela aproximação/ apropriação (desvelamento) com essa área de conhecimento.

O segundo momento da formação foi o da dinâmica da leitura do grupo - construção do perfil da turma. No quadro da sala de aula, foi registrada a apresentação que os docentes realizaram sobre os colegas, organizados em duplas, sendo socializada, para o grande grupo, a experiência profissional dos presentes na Educação Superior e principal qualidade observada em sua prática docente. Com base nessa dinâmica, delineamos que significativa maioria de professores (75\%) tinha pouca ou nenhuma experiência docente, o que de pronto confirmou a importância e necessidade da realização do Curso. Evidenciaram-se, também, as diferentes características reconhecidas por cada docente, o que levou a pensar na necessidade do desenvolvimento das riquezas presentes na diversidade dos participantes; na potencialidade que temos enquanto grupo; nas 
coisas diferentes que podemos fazer aproveitando a habilidade de cada um etc., conforme manifestado pela professora-mediadora do Curso, "Quanto mais o grupo de professores trabalhar junto, tanto melhor". Constatação que nos leva a afirmar com Franco, a necessidade de que "[...] os docentes encontrem espaços de acolhimento e de sustentação institucional; tenham espaços coletivos para participarem de processos colaborativos de construção/reconstrução das práticas que aninham e potencializam sua ação pedagógica”. (FRANCO, 2012, p. 23).

A reflexão seguinte proposta pela professora-mediadora foi para que os cursistas se manifestassem acerca de como é percebido o desempenho dos estudantes na graduação. As explanações iniciais versaram sobre a heterogeneidade das turmas, o que demanda repensar os currículos universitários, incluindo acompanhamento aos estudantes no início do semestre letivo, através de verificação diagnóstica que auxilie na tomada de decisão acerca de como os estudantes podem superar as lacunas/dificuldades. Conforme apontado pela professora-mediadora: "Se os alunos não sabem ler, interpretar... é preciso desenvolver um projeto de estudo de texto; não importa qual componente... se cada professor fizer isto uma vez por semana, com certeza dará resultados". Essa observação, em nosso entendimento, corrobora com a organicidade das características do saber-fazer docente apregoadas por Zabala (2004). Segundo o referido autor, algumas características do saber-fazer docente podem ser elencadas: - alto nível de conhecimento do professor em sua matéria; - habilidades comunicativas do professor; - envolvimento, compromisso, interesse e preocupação com aprendizagem dos estudantes, o que Almeida (2012, p. 104) denomina de "profissionalidade docente". Tais características da ação docente passam a constituir o "campo da prática quando o professor assume a importância de reconhecer o perfil de seus alunos; identificar seus conhecimentos prévios, interesses e necessidades, [...] entre tantos outros requisitos para a boa docência”. (ALMEIDA, 2012, p. 104-105).

Também foi reconhecido que o ponto de partida do trabalho educativo deve ser a realidade. Segundo a professora-mediadora do Curso, "O conhecimento do grupo de trabalho é fundamental. A partir desse, percebem-se metas, conteúdo, perfil profissional. É importante ter em mente de onde vamos 'partir' para 'chegar' aonde queremos". Conhecido o contexto, é preciso trabalhar o que os estudantes não sabem, o que requer tempo para revisão de conteúdo. Essa flexibilidade, como os demais elementos do currículo, deve estar prevista no projeto político-pedagógico de curso. Vale registrar as palavras de Anastasiou, em obra dedicada aos processos de ensinage ${ }^{2}$ na Universidade:

2 O termo ensinagem é "usado para indicar uma prática social complexa efetivada entre os sujeitos, professor e aluno, englobando tanto a ação de ensinar quanto a de apreender, em um processo 
Nesse processo, o envolvimento dos sujeitos, em sua totalidade, é fundamental. Além do o quê e do como, pela ensinagem deve-se possibilitar $o$ pensar, situação em que cada estudante possa reelaborar as relações dos conteúdos, por meio dos aspectos que se determinam e se condicionam, mutuamente, numa ação conjunta do professor e dos alunos, com ações e níveis de responsabilidades próprias e específicas, explicitadas com clareza nas estratégias selecionadas. (ANASTASIOU; ALVES, 2012, p. 20).

Nesse contexto reflexivo, outro elemento importante surgido na formação foi a necessidade de responsabilizar o estudante pela caminhada que ele está fazendo; em vez de enfatizarmos a falta de engajamento dos estudantes, registramos a necessidade de ensiná-los a ter autonomia para buscar o que precisam. Essa observação suscitou a percepção da pertinência/necessidade de articulação entre a universidade e o Ensino Médio. Foi apontado que os estudantes chegam ao ensino universitário com bastante dificuldade de leitura, interpretação, redação, cálculo, etc.; dificuldades que passam a ser um "problema" que deve ser enfrentado (como desafio didático-pedagógico) pela universidade, para além de um fatalismo. Esse aspecto também é abordado por Almeida, no qual registramos aqui:

Outro aspecto da dimensão educadora que ancora o trabalho docente é a atenção que precisa ser dada a aspectos aparentemente bastante simples no contexto da formação dos alunos, como "ler", "escrever" e "estudar". [...]. A leitura é condição primeira para o desenvolvimento do estudo. [...]. A capacidade de leitura é requisito para o domínio da escrita e para o estudo. A escrita por sua vez é conteúdo imprescindível em si mesmo e é, ao mesmo tempo, considerada indispensável na aprendizagem de outros conhecimentos acadêmicos. [...]. Igualmente importante é ajudar os jovens a entender que estudar envolve intenso trabalho interior com textos, questões, exercícios e experiências, os quais reconfiguram suas compreensões e apropriações. (ALMEIDA, 2012, p. 105-107).

Conforme também salientou a professora-mediadora do Curso: "Professores estão no setor público, precisam assimilar esta realidade e o seu papel como parte da instituição". Em especial, foi explicitado pelos docentes que a maioria 
dos estudantes só desenvolve as resenhas, sínteses e outras atividades quando são avaliados e que, quando o fazem, são observadas muitas cópias da internet; assim foi discutida a inevitabilidade de trabalhar o que é compromisso, plágio e ética de forma concomitante aos conteúdos acadêmicos e das áreas de formação.

Ainda, com relação à abordagem dos conteúdos das diversas áreas do saber e do ensino, o Curso proporcionou a compreensão de que não há conteúdo neutro, mas conteúdo relacionado à profissão (ensino aplicado) e, para a escolha adequada dos mesmos, faz-se necessário consultar um profissional da área no momento de definir quais são os conteúdos aplicáveis à profissão. Conforme manifestou a professora-mediadora: "O conteúdo só vira saber quando há sabor". Sua afirmação corrobora com publicação anterior:

Trabalhando com os conhecimentos estruturados como saber escolar, é fundamental destacar o aspecto do saber referente ao gosto ou sabor, do latim sapere-ter gosto. Na ensinagem, o processo de ensinar e apreender exige um clima de trabalho tal que se possa saborear o conhecimento em questão. O sabor é percebido pelos estudantes quando o docente ensina determinada área que também saboreia, na lida cotidiana profissional e/ ou na pesquisa, e a socializa com seus parceiros na sala de aula. Para isso, o saber inclui um saber o quê, um saber como, um saber por quê e um saber para quê. (ANASTASIOU; ALVES, 2012, p. 20).

\section{Construção do conhecimento}

Após as mobilizações iniciais que pautaram e evidenciaram aos participantes a matriz teórico-conceitual adotada pelo Curso e pela Universidade, passou-se ao adensamento da temática da docência universitária com a fundamentação teórica. Assim, a construção do conhecimento na formação pedagógica foi desenvolvida com trabalhos em grupos, para revisão/adequação à realidade de pontos essenciais do projeto político-pedagógico de curso, tais como o perfil do egresso, objetivos, ementas, conteúdos e avaliação. Durante a apresentação dos grupos, percebemos um consenso entre os cursos: é necessário fazer conversar diferentes componentes curriculares para abordar aquilo que o estudante precisa realmente.

No caso da matriz curricular de alguns cursos, trazidos à discussão acerca do projeto político-pedagógico, o coletivo de participantes evidenciou sua percepção de que os componentes curriculares voltados à formação profissional 
estavam localizados na segunda metade do curso de graduação, o que dificultava a identificação/fidelização do acadêmico com o curso e contribuía para a desistência.

Nesse contexto, a formação pedagógica proporcionada pelo Curso não estava descolada dos aspectos do desenvolvimento profissional, como a compreensão do significado de elaborar e constantemente atualizar o projeto político-pedagógico, documento que revela a identidade de um curso de graduação. Como analisa Nóvoa (1999), se a formação não ocorre articulada com os demais aspectos do desenvolvimento profissional e com as novas possibilidades formativas pensadas para responder ao dinâmico processo de mudanças sociais e educacionais, acabará apenas por adicionar mais atribuições à sobrecarga imposta aos docentes na atualidade.

Entre as temáticas desenvolvidas no momento da construção de conhecimentos, destacamos a da avaliação. Iluminar, intervir, investigar, compreender e tomar decisões foram compreensões dos participantes, que assumiram o comum entendimento de "prova" ou "teste" como instrumentos avaliativos. Em especial, chamou atenção do grupo a consideração trazida pela professora-mediadora de que, quando o estudante é avaliado, também o professor, o currículo e todo o curso estão sendo avaliados. Nesse sentido, esse momento de avaliação do processo ensino-aprendizagem deve ser planejado considerando sua relação com os objetivos do curso, do componente curricular, do professor e do estudante.

\section{Síntese do conhecimento}

Com base na perspectiva dialética, o Curso de Formação Pedagógica propiciou que os participantes conhecessem teoricamente e vivenciassem uma alternativa para o processo de construção do conhecimento em sala de aula, a partir do desenvolvimento das etapas de: (a) mobilização para o conhecimento; (b) construção do conhecimento e (c) elaboração e expressão da síntese do conhecimento. Assim, um ponto alto da formação foi a aproximação com a metodologia dialética, trazida com base nos estudos de Vasconcellos (1993):

Uma metodologia na perspectiva dialética baseia-se na concepção de homem e de conhecimento onde se entende o homem como um ser ativo e de relações. Assim, compreende-se que o conhecimento não é "transferido" ou "depositado" pelo outro (conforme a concepção tradicional), 
nem é “inventado" pelo sujeito (concepção espontaneísta), mas sim construído pelo sujeito na sua relação com os outros e com o mundo. (VASCONCELLOS, 1993, p. 45).

Devidamente exercitada pelos participantes do Curso, o planejamento e a socialização de estratégias de ensinagem ocorridas nessa formação, compreenderam as seguintes atividades, entre outras: aula expositiva tradicional; aula expositivo-dialogada; uso de vídeo e imagens; dinâmica de brainstorm; seminário; roda de conversa; encenações; prática - experimentos; resolução de problemas; trabalho em grupos; textos para interpretação; pesquisa; simuladores; modelagem; apresentação com intervenção do aluno; formulação de questões etc. A construção da ensinagem foi orientada para que os docentes, em grupo, estabelecessem moderadores, escribas e relatores.

Em suma, a análise nos permite concordar com Almeida e fortalecer seu argumento de que: "[...] a formação docente do ensino superior e o sucesso do seu desenvolvimento profissional resultam da combinação de seu interesse e engajamento pessoal com a responsabilidade institucional de assegurar e valorizar possibilidades formativas por meio de ações políticas e de gestão.". (ALMEIDA, 2012, p. 29).

\section{Considerações finais: perspectivas para a formação do docente universitário}

A análise dos registros dos encontros de formação pedagógica evidenciou a presença dos seguintes elementos constitutivos da ação docente:

(a) reflexões sobre a necessidade de revisão dos currículos, a partir da realidade, tendo como foco o protagonismo e a autonomia estudantis na/da trajetória acadêmica;

(b) atualização do projeto político-pedagógico de curso, com foco no perfil almejado do egresso, a partir da revisão de objetivos, ementas, conteúdos, metodologias, processos de acompanhamento e avaliação discente;

(c) avaliação contínua do curso de graduação e dos sentidos pedagógicos inerentes à docência universitária.

Compartilhamos nossa compreensão de que a presença desses elementos constitutivos da ação docente evidenciou contribuições à prática dos docentes universitários participantes dos encontros de formação pedagógica. Adicional- 
mente, a formação docente realizada nos Campi sinalizou para a potencialidade de formação com a participação de docentes universitários de diferentes áreas do conhecimento: Ciências da Saúde; Ciências Sociais Aplicadas; Ciências Agrárias; Engenharias; Ciências Exatas e da Terra; Ciências Humanas; Linguística, Letras e Artes.

Ainda que apenas iniciada a percepção e discussão dos professores universitários aos referenciais que fundamentam pedagogicamente suas ações educativas, o acesso às condições para realização da ensinagem assentada no exercício da crítica e da autocrítica, bem como a proposição de espaços e tempos para compreensão mais ampla e articulada das dimensões epistemológicas e metodológicas da prática docente, constituem-se em conhecimentos científicos necessários aos professores universitários (ALMEIDA, 2012, p. 96-97).

Esta análise estimulou-nos a afirmar o compromisso da gestão institucional com a promoção de condições para a formação pedagógica, visto as manifestações que evidenciaram aspectos intrínsecos do desenvolvimento profissional e seu significado enquanto prática social.

Além disso, cabe destacar a coerência da professora-mediadora na realização do Curso em consonância com a metodologia dialética para (re)construção de conhecimentos, destacando-se as provocações iniciais precedidas por espaços de construção de entendimento sobre o saber-fazer docente, com ênfase nos elementos dos projetos político-pedagógicos e estratégias de ensinagem; e a consideração dos estágios de elaboração e síntese do conhecimento e o nível de turma (participantes) quanto aos conteúdos trabalhados, expresso na avaliação oral manifestada pelos participantes, no final dos encontros formativos. Em nossa avaliação, essa postura é importante para aumentar o nível de consciência de si, proporcionadas em ocasião de formação universitária.

\section{REFERÊNCIAS}

ALMEIDA, M. I. de. Formação de Professor do Ensino Superior: desafios e políticas institucionais. 1. ed. São Paulo: Cortez, 2012.

ALMEIDA, M. I. de; PIMENTA, S. G. A Construção da Pedagogia Universitária no âmbito da Universidade de São Paulo. In: PIMENTA, S. G.; ALMEIDA, M. I. de. Pedagogia Universitária: caminhos para a formação de professores. São Paulo: Cortez, 2011. p. 19-43.

ANASTASIOU, L.; ALVES, L. P. Processos de Ensinagem na Universidade: pressupostos para as estratégias de trabalho em aula. 10. ed. Joinville: Univille, 2012. 
BARBIER, R. A Pesquisa-ação. 8. ed. Brasília: Liber Livro Editora, 2007.

BRASIL. Presidência da República. Casa Civil. Decreto nº 6.096, de 24 de abril de 2007. Institui o Programa de Apoio a Planos de Reestruturação e Expansão das Universidades Federais - REUNI. Brasília: Casa Civil, 2007.

CUNHA, M. I. da (Org.). Pedagogia Universitária: energias emancipatórias em tempos neoliberais. Araraquara: Junqueira \& Marin, 2006.

DINIZ-PEREIRA, J. E. A formação acadêmico-profissional: compartilhando responsabilidades entre as universidades e escolas. In: ENCONTRO NACIONAL DE DIDÁTICA E PRÁTICA DE ENSINO: trajetórias e processos de ensinar e aprender: didática e formação de professores, 14., 2008. Anais... Porto Alegre: EDIPUCRS, 2008. p. 253-267.

DUQUE-ARRAZOLA, L. S.; THIOLLENT, M. J. M. (Org.). João Bosco Guedes Pinto. Metodologia, teoria do conhecimento e pesquisa-ação: textos selecionados e apresentados. Belém: UFPA (Instituto de Ciências Sociais Aplicadas), 2014.

FRANCO, M. A. Apresentação. In: ALMEIDA, M. I. de. Formação de Professor do Ensino Superior: desafios e políticas institucionais. 1. ed. São Paulo: Cortez, 2012. p. 21-25.

FREIRE, P. Política e Educação: ensaio. 6.ed. São Paulo: Cortez, 2001.

MORAES, R.; GALIAZZI, M. do C. Análise textual discursiva. Ijuí: Ed. Unijuí, 2007.

NÓVOA, A. Os professores na virada do milênio: do excesso dos discursos à pobreza das práticas. Educação e Pesquisa, São Paulo, v. 25, n. 1, p. 11-20, 1999.

PIMENTA, S. G. Apresentação da Coleção Docência em Formação. In: ALMEIDA, M. I. de. Formação de Professor do Ensino Superior: desafios e políticas institucionais. 1. ed. São Paulo: Cortez, 2012.

RIOS, T. A. Compreender e Ensinar: por uma docência da melhor qualidade. 7. ed. São Paulo: Cortez, 2008.

THIOLLENT, M. Pesquisa-ação no campo da comunicação sócio-política. Revista Comunicação e Sociedade, São Bernardo do Campo: UMESP, n. 4, p. 63-79, 1980.

THIOLlenT, M. Metodologia da pesquisa-ação. 8. ed. São Paulo: Cortez, 1998.

VASCONCELLOS, C. dos S. Construção do conhecimento em sala de aula. São Paulo: Editor Libertad, 1993.

ZABALA, M. La Enseñanza Universitária: el encenario y sus protagonistas. Madrid: Narcea, 2004.

Texto recebido em 28 de março de 2017. Texto aprovado em 31 de outubro de 2017. 
